\title{
Acting on incidental findings in research imaging
}

Incidental findings of imaging research studies can turn healthy individuals into anxious patients, while putting an extra burden on primary care. $\mathbf{J} \mathbf{M}$ Wardlaw and colleagues argue that doctors should ensure that the personal, ethical, healthcare, and cost implications of these common findings are managed proportionately, sensitively, and economically

\section{J M Wardlaw professor of applied neuroimaging and honorary consultant neuroradiologist ${ }^{1}, \mathrm{H}$ Davies research ethics adviser ${ }^{2}$, T C Booth consultant neuroradiologist ${ }^{3}$, G Laurie professor of medical jurisprudence ${ }^{4}$, A Compston professor of neurology ${ }^{5}$, C Freeman professor of psychiatry and clinical lead for accreditation ${ }^{6}$, M O Leach professor of physics as applied to medicine ${ }^{7}$, A D Waldman consultant neuroradiologist and research director for imaging ${ }^{8}$, D J Lomas professor of clinical MRI ${ }^{9}$, $\mathrm{K}$ Kessler professor of cognitive neuroscience ${ }^{10}$, $\mathrm{F}$ Crabbe senior research radiographer ${ }^{11}$, A Jackson professor of radiology ${ }^{12}$}

${ }^{1}$ Division of Neuroimaging Sciences, Centre for Clinical Brain Sciences, University of Edinburgh, Edinburgh EH16 4SB, UK; ${ }^{2}$ Health Research Authority, Skipton House, London; ${ }^{3}$ Department of Neuroradiology, King's College Hospital NHS Foundation Trust, Denmark Hill, London; ${ }^{4} \mathrm{JK}$ Mason Institute for Medicine, Life Sciences and the Law, School of Law, University of Edinburgh; ${ }^{5}$ Department of Clinical Neurosciences, University of Cambridge; ${ }^{6}$ College Centre for Quality Improvement, Royal College of Psychiatrists, London; ${ }^{7}$ Cancer Research UK Cancer Imaging Centre, Institute of Cancer Research and Royal Marsden Hospital, London; ${ }^{8}$ Department of Imaging, Imperial College London; ${ }^{9}$ Department of Radiology, University of Cambridge and Addenbrooke's Hospital, Cambridge Biomedical Campus; ${ }^{10}$ Aston Brain Centre, School of Life and Health Sciences, Aston University, Birmingham; ${ }^{11}$ Institute of Neuroscience and Psychology, University of Glasgow; ${ }^{12}$ Wolfson Molecular Imaging Centre, University of Manchester

Medical imaging is commonly used in research and can lead to major medical advances. However, it can also detect incidental findings of "potential health importance, unknown to the participant, unrelated to the purpose, and beyond the aims of the research." ${ }^{2}$ Detecting incidental findings may be lifesaving or may cause distress and uncertainty and affect livelihood. Incidental findings increase the already high workloads of general practitioners and hospital specialists. ${ }^{3}$ They have immediate and emotive impact: participants know that the researcher sees the images during scanning, so they expect that incidental findings will be acted on, even when told otherwise. ${ }^{5}$ Researchers' knowledge of incidental findings varies hugely. ${ }^{67}$ Little advice is available on what to do, despite calls for clarity and for national frameworks. ${ }^{8-13}$ Efforts to establish guidance on incidental findings by UK imaging researchers, the UK Biobank Ethics and Governance Council, the Wellcome Trust, the Medical Research Council, and the Health Research Authority put the United Kingdom ahead of other countries, ${ }^{14-16}$ but gaps in our knowledge remain (box 1).

On average, $3 \%$ of healthy participants who undergo brain imaging have incidental findings with health implications, rising to nearer $30 \%$ over age 70 or with more sensitive imaging. ${ }^{17-24}$
Incidental findings in the chest or abdomen are found in $14 \%$ to $50 \%$ of patients ${ }^{23} 25$ and $29 \%$ to $94 \%$ of volunteers, ${ }^{26} 27$ particularly with cardiac and colon imaging. ${ }^{28-30}$ Physiological anomalies and artefacts may be misidentified as disease by researchers without specialist medical training.

Major research initiatives in the UK (such the UK Biobank Imaging study, with up to 100000 participants), the United States (the BRAIN Initiative), ${ }^{31}$ and many European countries will soon scan several hundred thousand healthy participants, generating many thousands of incidental findings. These will have a huge impact on primary care and hospital services and will bring research imaging into disrepute if the duty of care to participants goes unrecognised. ${ }^{1}$

Here we discuss the wide ranging personal, ethical, healthcare, and cost implications of incidental findings and suggest the path forward to avoid turning healthy individuals into anxious patients and burdening healthcare systems with even more overdiagnoses.

\section{Huge practical implications}

Recognising potential abnormalities requires specific medical expertise, but at least $40 \%$ of research imaging is undertaken 


\section{Box 1: Knowledge gaps}

Epidemiology of incidental findings with health consequences-Frequency, natural course, lifetime health, psychological and financial consequences of incidental findings, including those that are age and gender specific

How to manage costs_-Cost effectiveness of different management strategies

How research participants think about incidental findings-Attitudes of a wider cross section of research participants about management Better ways to inform research participants about medical and non-medical implications-Methods to improve participant understanding that further investigation and treatment may lead to substantial harm, not just benefit

How to improve engagement with healthcare providers-Hospital and primary care services should understand the practical and resource implications and join the discussion on management

Non-medical implications-Psychological, emotional, and personal financial effects of different management strategies

by non-medically trained scientists, potentially leading to incorrect diagnoses and costs to the participant, researchers, and the NHS. ${ }^{6-8}{ }^{10}{ }^{31-34}$ Without clearly established management pathways, the burden is likely to fall disproportionately on primary care.

Delays adversely affect participants' quality of life, insurance, and work. Some incidental findings require medical intervention and some trigger further investigations, both of which increase cost, risk, and anxiety. ${ }^{35}{ }^{36}$ For example, a volunteer with an unsuspected ascending aortic aneurysm (but family history of sudden death before age 40) benefited from intensive management of cardiovascular risk factors (fig $1 \Downarrow$ ). Other examples include a young volunteer with unsuspected multiple sclerosis who benefited from early prescription of disease modifying therapy (fig $2 \Downarrow$ ) and a volunteer with a liver lesion, probably benign, who is now having annual liver magnetic resonance imaging (MRI) to avoid biopsy (fig $3 \Downarrow$ ). Another volunteer with a third ventricular colloid cyst was given advice in case symptoms developed (fig $4 \Downarrow$ ). In another case a volunteer had major restrictions placed on his pilot's licence after imaging detected an asymptomatic brainstem lesion, probably developmental perivascular spaces (fig $5 \Downarrow$ ).

\section{What do participants expect?}

Data from potential participants indicate that most want to be informed of incidental findings with health relevance in person, by an expert who knows what to do. ${ }^{57}{ }^{38}$ In one study of 133 volunteers $41 \%$ said they would participate only if they received feedback about all potential problems. ${ }^{39}$ In another study $79 \%$ of 1105 respondents thought that the advantages of feedback outweighed the disadvantages, regardless of curability, $71 \%$ thought that feedback should be included in the consent process, $60-70 \%$ recognised inaccurate findings or loss of insurance as among the main disadvantages, and most thought that it was acceptable to override refusal to receive feedback if the condition was potentially life threatening. ${ }^{5}$

The attitudes of those who have participated in research vary. When 1672 participants in UK Biobank were told that planned additional brain and body imaging would not be a health check, would be stored for future research, and would not be reviewed routinely, but that their doctor would be notified if a potentially serious abnormality was noticed during scanning, 1572 of them (92\%) agreed to participate. ${ }^{40}$ In a longitudinal study of atheroma only $0.02 \%$ of 4500 participants aged $40-54$ asked not to receive feedback. ${ }^{41}$ We need more data on participants' understanding and experiences of research imaging.

\section{Natural course is unknown}

Predicting prognosis of incidental findings would be more accurate if our knowledge of prevalence by age, natural course, and medical implications had progressed at the same pace as the sensitivity of imaging technologies. But for many incidental findings the benefit versus risk of early diagnosis and treatment is unknown. Only five studies provide data on long term natural course of incidental findings detected during research imaging. In a retrospective analysis of 1000 healthy participants aged 3-83 years who had brain MRI, 180 had incidental findings, 18 of whom went for routine assessment and 11 for urgent medical assessment—but the outcomes are unknown. ${ }^{42}$ In another study $32 \%$ of 750 volunteers aged $71-74$ had an abnormal brain scan, $2 \%$ went for further assessment, and none received treatment. ${ }^{18}$ Incidental findings on body imaging are investigated and treated more often than those on brain imaging. Twenty four of 124 (18\%) incidental findings in 132 healthy doctors on whole body MRI were investigated: five were tumours, of which two were malignant. ${ }^{27}$ Fifteen of 101 (15\%) incidental findings in 254 volunteers on coronary magnetic resonance angiography were referred for further imaging. ${ }^{29}$ In a study of 2500 community participants who had whole body MRI, 1052 incidental findings were confirmed and fed back to the participants, 62 of which (6\%) were malignant, 383 (36\%) were benign, 607 (58\%) were unclear, and only $9(0.7 \%)$ were treated..$^{22}$

\section{Legal precedents are unclear}

How the medical profession responds to research detected incidental findings is important. In the absence of a legal "test case" in the UK, courts will take common practice and relevant professional bodies' views into account, enabling the profession to influence legal precedent. ${ }^{43}{ }^{44}$ Although doctors and other healthcare professions have a well established duty of care to tell patients about clinically relevant findings, its scope is less well defined for research or for findings of unknown relevance. ${ }^{4445}$ Some duty of care in research undoubtedly exists-what constitutes a reasonable standard of care depends on what responsible peers consider acceptable. It may be informed by the researcher's professional status, experience, and potential to prevent harm.

Reasonable care in research is likely to include informing participants of treatable incidental findings and enabling them to benefit from earlier, perhaps more effective, treatment. ${ }^{44}$ Many would argue that the absence of a clear, ethically sound, transparent policy on incidental findings is irresponsible. What if a lesion that could precipitate epilepsy was seen in a commercial driver who had refused feedback? The response should be measured, proportionate to risks (including risks to research), based on actual rather than perceived risks, and should avoid increasing the administration and cost of research and overdiagnoses.

\section{Who pays?}

UK primary care currently carries the major burden of referring and counselling the worried, previously healthy participant who 
has become a patient based on incidental findings. Total costs and cost effectiveness of managing incidental findings are unknown. ${ }^{28} 46$ The Wellcome Trust and MRC have agreed to support the costs of providing feedback on incidental findings in research that they fund, but identification is only the first step and much imaging research is funded by bodies who have not made such a commitment. ${ }^{48-50}$

Countries where private healthcare predominates may inadvertently be fostering "research tourism." Worried individuals might participate in imaging research for the "free scan," not knowing that the imaging may be inappropriate, that the researchers may not be competent to interpret the findings, or the cost implications of any additional management of incidental findings.

\section{What now?}

We must acknowledge the existence of research detected incidental findings and implement pragmatic and proportionate ways of dealing with them. The expectations of participants should be managed to avoid research imaging being seen as a "health check" and to prevent false reassurance if no feedback is received. ${ }^{451}$ They should understand the potential for anxiety, health, and personal financial risks. ${ }^{40}$

Radiologist review of incidental findings is impractical owing to the high rates of research imaging, insufficient radiologists with already large clinical demands, and expense. ${ }^{7}$ Remote review of images via a network of trained individuals who provide quick advice on findings has worked in some places but needs organisation and incurs cost. ${ }^{52}$ No alternatives are in widespread use. ${ }^{53-56}$ Perhaps non-expert researchers could benefit from a list of common incidental findings with their health implications. But such a list needs developing, validating, and testing for legal implications, with the associated costs, and requires more knowledge of natural course.

A workshop of UK researchers, professional organisations, ethicists, and funders of imaging research in 2011 developed six working principles to aid planning around research detected incidental findings (box 2). ${ }^{14}$ We may need mechanisms for handling new health implications of former research findings - for example, features subsequently found to be treatable with new interventions - which raises questions of dynamic consent and re-identification mechanisms. ${ }^{57}$

Further discussion on management of incidental findings must include NHS representatives (and relevant representatives from other countries) who, with a few exceptions, have largely been omitted from the debate. ${ }^{14}$ Incidental findings should be part of good clinical practice training. New research imaging centres should plan for medical input to research imaging.

We depend on the public for participants in research; they should understand the implications of sensitive imaging technologies so they can interact with them in an informed way. Participants should understand that all research, while potentially conferring major societal benefits, carries risks, and that detailed feedback can have a negative impact on both research and health services. Responsible use of powerful research technologies now demands national foresight and proactive informed debate to promote trust in research, and the results, without unduly encumbering the scientific process. ${ }^{1}$

\section{Contributors and sources: JMW, AJ, ADW, and TCB are} neuroradiologists; DJL is a general radiologist; $H D$ advises the Health Research Authority on ethics and developed advice for research ethics committees; GL is a lawyer specialising in technologies and chaired the
UK Biobank Ethics and Governance Council; AC is a neurologist; CF is a psychiatrist; $\mathrm{K}$ Kessler is a neuroscientist; $\mathrm{MOL}$ is a medical physicist; and $\mathrm{FC}$ is a research radiographer. JMW, AJ, TCB, AC, CF, MOL, ADW, DJL, KK, and FC have extensive experience of using imaging in research. JMW and AJ contributed equally to this work. JMW, AJ, TCB, and ADW designed the workplan, collected background data, and organised discussion among experts. $\mathrm{CF}, \mathrm{AC}, \mathrm{ADW}$, and $\mathrm{MOL}$ chaired discussions. DL, $\mathrm{HD}, \mathrm{KK}$, and FC provided important background information. JMW, AJ, TCB, HD, and GL drafted the paper. All authors revised the paper and approved the final version for publication. JMW and $\mathrm{AJ}$ are guarantors.

Funding: The Wellcome Trust, the Royal College of Radiologists, and the Scottish Funding Council through the Scottish Imaging Network, A Platform for Scientific Excellence (www.SINAPSE.ac.uk) funded the UK discussion of incidental findings in research imaging in 2011, including preparation and follow-up of a one day consensus meeting and subsequent publication of a report that led to this paper. This manuscript was prepared independently of the funders, who also took no role in the decision to submit for publication. The authors hold the data.

Competing interests: We have read and understood BMJ policy on declaration of interests and declare the following: AJ, JMW, ADW, and MOL have responsibility for research imaging centres that conduct clinical research on patients and participants and receive funding from government, charitable, and industrial sources. The other authors have no relevant interests to declare.

Provenance and peer review: Not commissioned; externally peer reviewed.

Illes J, Kirschen MP, Edwards E, et al. Incidental findings in brain imaging research Science 2006;311:783-4

2 Wolf SM, Lawrenz FP, Nelson CA, et al. Managing incidental findings in human subjects research: analysis and recommendations. J Law Med Ethics 2008;36:219-48.

3 Warlow C. The new religion: screening at your parish church. BMJ 2009;338:b1940.

4 Stone HJ. Incidentalomas-clinical correlation and translational science required. N Engl $J$ Med 2006;26:2748-9.

5 Wellcome Trust, Medical Research Council, Opinion Leader. Assessing public attitudes to health related findings in research. 2012. www.wellcome.ac.uk/stellent/groups/ corporatesite/@msh grants/documents/web document/wtvm055196.pdf.

6 Illes J, Kirschen MP, Karetsky K, et al. Discovery and disclosure of incidental findings in neuroimaging research. J Magn Reson Imaging 2004;20:743-7.

7 Booth TC, Waldman AD, Wardlaw JM, Taylor SA, Jackson A. Management of incidental findings during imaging research in "healthy" volunteers: current UK practice. Br J Radio 2012;85:11-21.

8 Booth TC, Jackson A, Wardlaw JM, Taylor SA, Waldman AD. Incidental findings found in "healthy" volunteers during imaging performed for research: current legal and ethical implications. Br J Radiol 2010;83:456-65.

9 Heinemann T, von Kummer R; German Society of Neuroradiology. Response of the German Society of Neuroradiology to the guideline "ethically appropriate reaction to incidental imaging findings in brain research," suggested by Thomas Heinemann, Institut für Wissenschaft und Ethik, and Christian Hoppe, Klinik für Epileptologie, Universität Bonn, Germany, on January 9, 2009. Klin Neuroradiol 2009:19:108-10.

10 Woodward $\mathrm{Cl}$, Toms AP. Incidental findings in "normal" volunteers. Clin Radiol 2009;64:951-3.

11 van der Lugt A. Incidental findings on brain magnetic resonance imaging. BMJ 2009;339:b3107.

12 Dilemmas posed by chance research results. New Scientist 2008 Jul 2. www.newscientist. com/article/mg19926632-900-editorial-dilemmas-posed-by-chance-research-results/.

13 Presidential Commission for the Study of Bioethical Issues. Anticipate and communicate. Ethical management of incidental and secondary findings in the clinical, research, and direct-to-consumer contexts. Dec 2013. www.bioethics.gov/node/3183.

14 The Royal College of Radiologists. Management of incidental findings detected during research imaging. 2011. www.rcr.ac.uk/management-incidental-findings-detected-duringresearch-imaging.

15 UK Biobank Ethics and Governance Council. Annual review 2013. http://egcukbiobank. org.uk/sites/default/files/EGC\%20annual\%20review\%202013.pdf.

16 Medical Research Council, Wellcome Trust. Framework on the feedback of health-related findings in research. Mar 2014.www.wellcome.ac.uk/stellent/groups/corporatesite/@ policy_communications/documents/web_document/wtp056059.pdf.

17 Morris Z, Whiteley WN, Longstreth WT Jr, et al. Incidental findings on brain magnetic resonance imaging: systematic review and meta-analysis. BMJ 2009;339:b3016.

18 Sandeman EM, Valdes-Hernandez MC, Morris Z, et al. Incidental findings on brain MR imaging in older community-dwelling subjects are common but serious medical consequences are rare. A cohort study. PLOS ONE 2013;8:e71467.

19 Hartwigsen G, Siebner HR, Deuschl G, Jansen O, Ulmer S. Incidental findings are frequent in young healthy individuals undergoing magnetic resonance imaging in brain research imaging studies: a prospective single-center study. J Comput Assist Tomogr 2010;34:596-600.

20 Looney AT, Nason GJ, McGuire BB, et al. Incidentalology: a developing urological sub-specialty. Surgeon 2014;12:301-6. 


\section{Box 2: Reasonable principles for management of incidental findings in research}

Transparency-Acknowledge the frequency and type of incidental findings likely to be encountered in the research and explain in protocols and to ethics committees the procedures for identifying, managing, and informing participants about such findings. Study information sheets and consent procedures should be clear on risk of, and procedures for managing, incidental findings

Expectations-Participants should know what to expect regarding frequency, type, identification, disclosure, further medical management and personal implications of incidental findings. Participant input to study design, information sheets, and consent processes is important Duty of care - The legal parameters of researcher duty of care remain under debate and untested in the UK. In the meantime, imaging research centres should have a clear policy on management of incidental findings and should communicate this to research participants at the time of recruitment, not only at the scanner. Researchers should avoid feeding back unverified results without an action plan, as this may increase anxiety

Resources-Resources are finite, so funders, ethics committees, research administrators, and healthcare providers should all be aware of staff and financial constraints

Flexibility —Relevant management will vary with research question, participant characteristics, researcher background, and integration with clinical services

Evolving field-Imaging technologies are increasingly sophisticated; medical knowledge advances rapidly; ambitious population imaging studies, expectations and rights of the individual, and access to medical information, all contribute to changing detection and implications of research incidental findings

\section{Key messages}

The burden of managing incidental findings detected by research imaging falls heavily on primary care (referral, counselling, treatment, etc)

Little advice is available on how to manage incidental findings, and legal precedents are yet to be established

We need more data on their natural course, the cost effectiveness of management strategies, and the attitudes of a cross section of research participants

Research participants should be supported to develop realistic expectations on the likelihood of detection and potential implications of incidental findings as part of the consent process

21 Furtado CD, Aguirre DA, Sirlin CB, et al. Whole-body CT screening: spectrum of findings and recommendations in 1192 patients. Radiology 2005;237:385-94.

22 Hegenscheid K, Seipel R, Schmidt $\mathrm{CO}$, et al. Potentially relevant incidental findings on research whole-body MRI in the general adult population: frequencies and management. Eur Radiol 2013;23:816-26.

23 Schaaf WE Jr, Patel Z, Retrouvey M, Cunningham TD, Johnson LS. Frequency and clinical relevance of PET/CT incidentalomas. Abdom Imaging 2014;39:657-62.

24 Sierink JC, Saltzherr TP, Russchen MJ, et al. Incidental findings on total-body CT scans in trauma patients. Injury 2014;45:840-4.

25 Lumbreras B, González-Alvarez I, Gómez-Sáez N, et al. Management of patients with incidental findings in imaging tests: a large prospective single-center study. Clin Imaging 2014;38:249-54

26 Morin SH, Cobbold JF, Lim AK, et al. Incidental findings in healthy control research subjects using whole-body MRI. Eur J Radiol 2009;72:529-33.

27 Lo GG, Ai V, Au-Yeung KM, Chan JK, Li KW, Chien D. Magnetic resonance whole body imaging at 3 Tesla: feasibility and findings in a cohort of asymptomatic medical doctors. Hong Kong Med J 2008;14:90-6.

28 MacHaalany J, Yam Y, Ruddy TD, et al. Potential clinical and economic consequences of noncardiac incidental findings on cardiac computed tomography. J Am Coll Cardiol 2009;54:1533-41.

29 Vogel-Claussen J, Li D, Carr J, et al. Extracoronary abnormalities on coronary magnetic resonance angiography in the multiethnic study of atherosclerosis study: frequency and clinical significance. J Comput Assist Tomogr 2009;33:752-4.

30 Siddiki H, Fletcher JG, McFarland B, et al. Incidental findings in CT colonography: literature review and survey of current research practice. J Law Med Ethics 2008;36:320-31.

31 Alivisatos AP, Chun M, Church GM, Greenspan RJ, Roukes ML, Yuste R. The brain activity map project and the challenge of functional connectomics. Neuron 2012;74:970-4.

32 Jackson A. Is academic radiology in the UK dead? A personal view. Imaging Managemen 2007. https://healthmanagement.org/c/imaging/issuearticle/is-academic-radiology-in-theuk-dead-a-personal-view.

33 Booth TC, Mehrzad H, Wardlaw JM, Jackson A, Gilbert FJ. Training the next generation of radiology researchers. Report on a joint meeting of the Royal College of Radiologists and the Wellcome Trust and an overview of college strategies in developing radiology research. Clin Radiol 2012;67:411-6.

34 Milstein AC. Research malpractice and the issue of incidental findings. J Law Med Ethics 2008;36:356-60.

35 Hayward R. VOMIT (victims of modern imaging technology)—an acronym for our times. BMJ 2003;326:1273.

36 Orme NM, Fletcher JG, Siddiki HA, et al. Incidental findings in imaging research: evaluating incidence, benefit, and burden. Arch Intern Med 2010;170:1525-32.

37 Kirschen MP, Jaworska A, Illes J. Subjects' expectations in neuroimaging research. $J$ Magn Reson Imaging 2006;23:205-9.

38 Vernooij MW, Ikram MA, Tanghe HL, et al. Incidental findings on brain MRI in the general population. N Engl J Med 2007;357:1821-8.
39 Brown M, Knight HM. Attitudes towards participating in $\mathrm{fMRI}$ studies amongst participants in a birth cohort study. 2010. www.cls.ioe.ac.uk/library-media\%5Cdocuments\%5CCLS WP_2010_8_.pdf.

40 UK Biobank. Biobank UK imaging sub-study incidental findings protocol. Version 25. Sep 2013.

41 Progression of early subclinical atherosclerosis. www.estudiopesa.org/en/index.php.

42 Katzman GL, Dagher AP, Patronas NJ. Incidental findings on brain magnetic resonance imaging from 1000 asymptomatic volunteers. JAMA 1999;282:36-9.

43 Mason JK, Laurie GT. Liability for medical injury. In: Mason JK, Laurie GT, eds. Mason and McCall Smith's Law and Medical Ethics. Oxford University Press, 2010: 122-71.

44 Belsky L, Richardson HS. Medical researchers' ancillary clinical care responsibilities. BMJ 2004:328:1494-6.

45 Miller FG, Mello MM, Joffe S. Incidental findings in human subjects research: what do investigators owe research participants? J Law Med Ethics 2008;36:271-9.

46 Ding A, Eisenberg JD, Pandharipande PV. The economic burden of incidentally detected findings. Radiol Clin North Am 2011:49:257-65.

47 Sadatsafavi M, Marra C, Li D, Illes J. An ounce of prevention is worth a pound of cure: cost-effectiveness analysis of incidentally detected aneurysms in functional MRI research. Value Health 2010;13:761-9.

48 Farrar J, Savill J. UK funders' framework for health-related findings in research. Lancet 2014;383:1954-5

49 Schmidt CO, Hegenscheid K, Erdmann P, et al. Psychosocial consequences and severity of disclosed incidental findings from whole-body MRI in a general population study. Eur Radiol 2013:23:1343-51.

50 Pinato DJ, Stavraka C, Tanner M, et al. Clinical, ethical and financial implications of incidental imaging findings: experience from a phase I trial in healthy elderly volunteers. PLOS ONE 2012;7:e49814.

51 Pickard JD, Gillard JH. Guidelines reduce the risk of brain-scan shock. Nature 2005;435:17.

52 Cramer SC, Wu J, Hanson JA, et al. A system for addressing incidental findings in neuroimaging research. Neuroimage 2011;55:1020-3.

53 Illes J, Kirschen MP, Edwards E, et al. Practical approaches to incidental findings in brain imaging research. Neurology 2008;70:384-90.

54 Berland LL, Silverman SG, Gore RM, et al. Managing incidental findings on abdomina CT: white paper of the ACR incidental findings committee. J Am Coll Radiol 2010;7:754-73.

55 Standardization critical to managing incidental findings. RSNA News 2011 Sep 1. www. rsna.org/NewsDetail.aspx?id=2422.

56 Illes J, Chin VN. Bridging philosophical and practical implications of incidental findings in brain research. J Law Med Ethics 2008;36:298-304

57 González DR, Carpenter T, van Hemert JI, Wardlaw J. An open source toolkit for medical imaging de-identification. Eur Radiol 2010;20:1896-904

Accepted: 25 September 2015

Cite this as: BMJ 2015;351:h5190

(c) BMJ Publishing Group Ltd 2015 


\section{Figures}

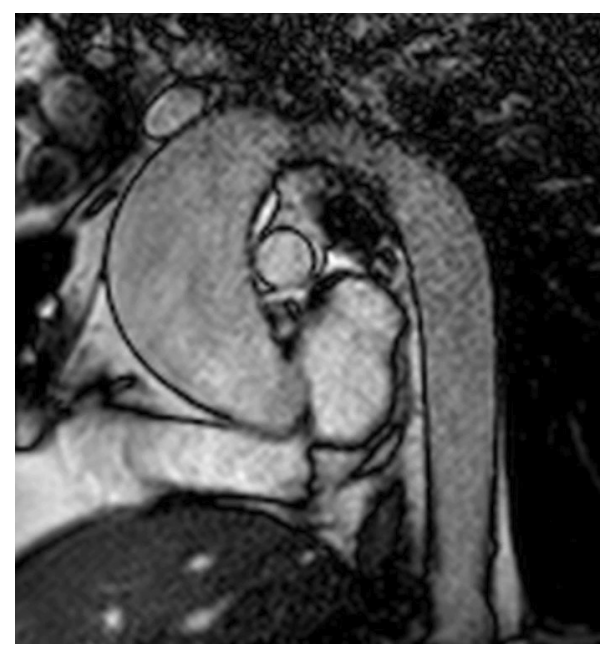

Fig 1 Unsuspected ascending aortic aneurysm detected in volunteer. All the first degree male relatives had died suddenly before the age of 40 , and intensive cardiovascular management was started

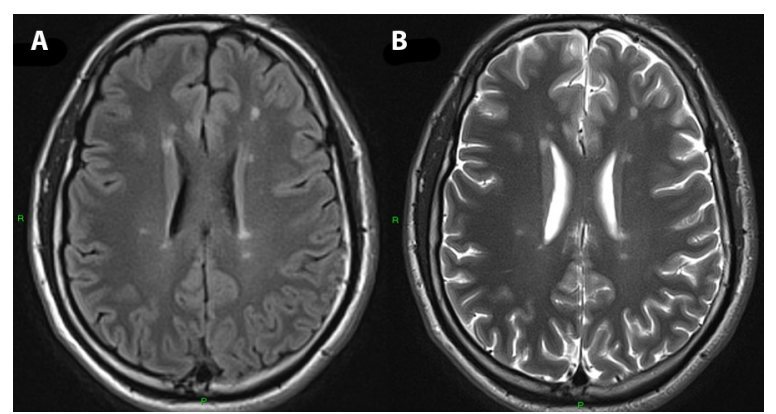

Fig 2 Axial FLAIR (left) and T2 (right) brain MRI show multiple lesions consistent with multiple sclerosis in a young health technologist, who benefited from early treatment

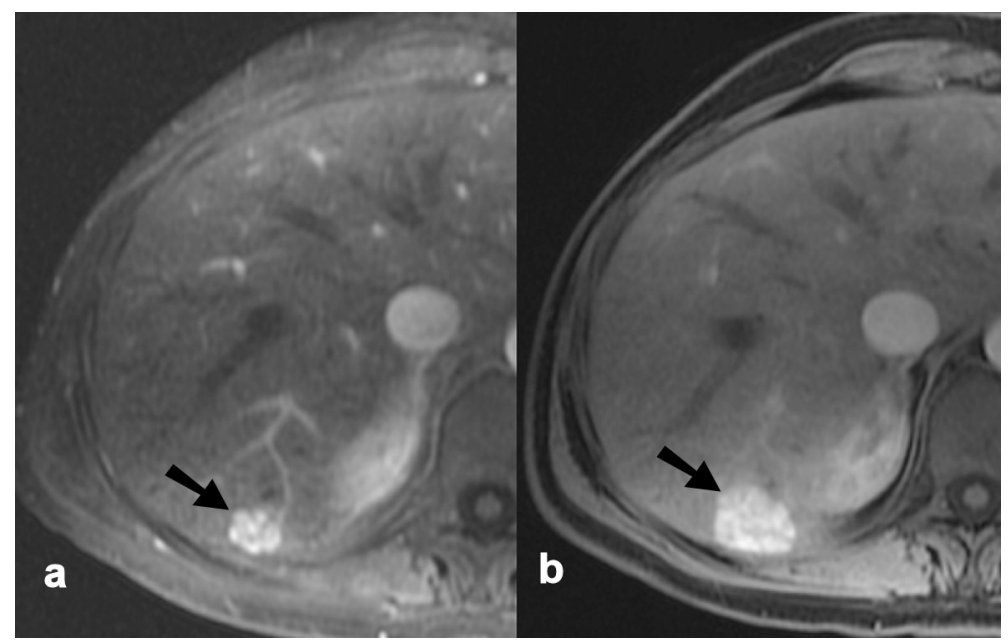

Fig 3 Uncertain liver mass in volunteer required annual follow-up. A 40 year old volunteer had a solid liver lesion found during a renal research MRI examination. A diagnostic MRI (left) suggested either focal nodular hyperplasia or adenoma. Annual follow-up examination at two years (right) showed lesion growth and atypical features. A biopsy to exclude adenoma (which carries a small risk of malignant change and spontaneous haemorrhage) was declined. The volunteer continues with annual follow-up MRI examinations 


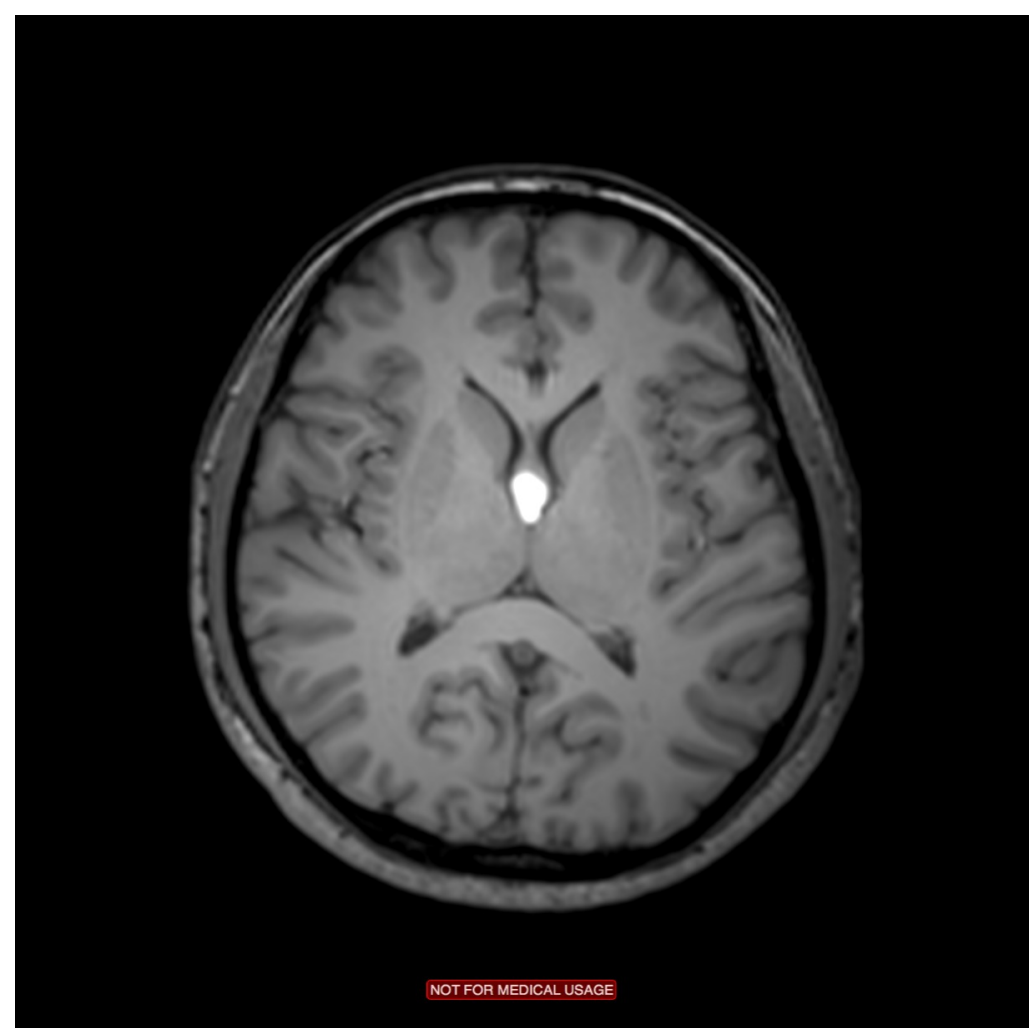

Fig 4 Third ventricular colloid cyst detected in research volunteer enabled advice to be given on how to respond to symptoms

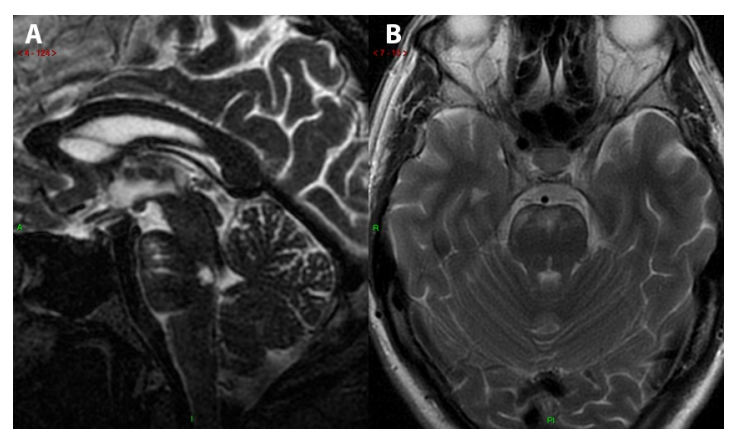

Fig 5 Adverse effect on employment for research volunteer. MRI showed a cluster of prominent perivascular spaces in the pons, initially interpreted as an ischaemic stroke despite absence of symptoms. This led to major restrictions on his pilot's licence 